\title{
« Une amie », fragment inédit d'une nouvelle annoncée
}

\author{
Roseline Garcia Ballester
}

\section{OpenEdition \\ Journals}

Édition électronique

URL : https://journals.openedition.org/coma/7739

DOI : $10.4000 /$ coma.7739

ISSN : 2275-1742

\section{Éditeur}

Institut des textes \& manuscrits modernes (ITEM)

\section{Référence électronique}

Roseline Garcia Ballester, « « Une amie », fragment inédit d'une nouvelle annoncée », Continents manuscrits [En ligne], 17 | 2021, mis en ligne le 15 octobre 2021, consulté le 08 janvier 2022. URL http://journals.openedition.org/coma/7739 ; DOI : https://doi.org/10.4000/coma.7739

Ce document a été généré automatiquement le 8 janvier 2022.

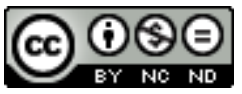

Continents manuscrits - Génétique des textes littéraires - Afrique, Caraîbe, dispora est mis à disposition selon les termes de la licence Creative Commons Attribution - Pas d'Utilisation

Commerciale - Pas de Modification 4.0 International. 


\title{
«Une amie », fragment inédit d'une nouvelle annoncée
}

\author{
Roseline Garcia Ballester
}

1 L'unique page retrouvée dans les archives René Maran de ce qui devait devenir la nouvelle Une amie (voir fig. 1) a attiré l'attention du groupe de travail Maran créé en 2020 au sein de l'équipe Manuscrits francophones de l'ITEM. Malheureusement, les recherches pour retrouver la partie manquante sont restées vaines. Aucune trace, ni dans la maison familiale de Poitiers, ni dans les archives conservées à Paris par le petitfils de l'écrivain.

2 Voici les renseignements dont nous disposons, grâce à la correspondance échangée entre Manoel Gahisto, l'ami fidèle, et René Maran.

3 Le 25 avril 1912, après un court séjour à Bordeaux, René Maran repart pour l'Afrique. Il est alors âgé de vingt-cinq ans. Il écrit :

Mes prochains livres, vous ai-je donné leurs titres probables? Les voici, Le livre du Souvenir, poèmes; Batouala le Makondji, roman indigène; Une amie, récit en termes et nuances psychologiques, sorte de contribution que j'essaie d'apporter à l'amitié amoureuse. Je me suis quelque peu autobiographié en ce manuscrit que je revois infiniment et corrige - ainsi que toutes mes productions ${ }^{1}$.

4 L'écriture de cette nouvelle occupe grandement René Maran pendant un certain temps. Le 26 novembre 1913, il écrit de Fort Sibut :

J'ai revu et mis à nouveau sur l'établi des chapitres de Batouala. le $\mathrm{M}$ et de Une amie. Bref, je n'ai pas perdu mon temps.

5 Presque deux ans après, il est toujours question de l'écriture de Une amie. On peut lire dans la lettre du 7 mars 1914, de Grimari :

Aux heures de souvenance mélancolique, j'affine les chapitres et les ébauches du petit roman psychologique Une amie, dont le héros, à certains moments, me ressemble à s'y méprendre.

Et encore, dans celle du 10 juin 1914 :

En ce moment, je fignole certains chapitres de Une amie. C'est une histoire d'amitié amoureuse. Je poursuis un peu partout sa réalisation... 
7 Manoel Gahisto reçoit donc des détails, régulièrement, sur l'avancée des travaux de l'auteur jusqu'en juin 1914. Puis le projet de rédaction de Une amie n'est plus du tout évoqué. Toute la question est évidemment de savoir pourquoi! Est-ce l'identité de cette mystérieuse amie qui empêche René Maran de faire publier la nouvelle? Quels sont ses scrupules? Pourquoi n'explique-t-il pas ce renoncement? Si pour une raison ou une autre, le document s'était perdu, on peut imaginer que Maran l'aurait regretté et mentionné.

D'où l'intérêt de l'hypothèse proposée par nos collègues, Roger Little et Charles Scheel : tous deux font l'hypothèse d'un « devenir » de Une amie dans le roman Un homme pareil aux autres. C. Scheel remarque notamment des ressemblances stylistiques et thématiques avec le passage consacré à Jacqueline. Je le cite:

J'avais dix huit ans. De cinq ou six ans plus âgée que moi, elle n'avait que la beauté de l'intelligence. Son nom? Jacqueline. Elle m'aimait. Je faisais semblant de l'ignorer. Je l'aimais. L'a-t-elle jamais su? Sans doute que non. J'étais trop jeune pour elle, n'avais pas encore fini mes études et me savais d'une race autre que la sienne ${ }^{2}$.

En complément, voici dans une lettre de 1913 un passage qui explicite ce que l'auteur comprend par l'expression « amitié amoureuse » :

De l'amitié amoureuse à l'amour, il n'y a qu'un pas à franchir. Ce sont déjà les mêmes baisers, les mêmes serrements de mains, les mêmes regards, les mêmes frissons du corps. Il n'y a que les étreintes qui soient incomplètes. Encore aujourd'hui, en fermant les yeux, je revois le contour des lèvres rouges, belles, moites et sensuelles et puis des yeux qui voulaient.

Comme j'ai été bête de ne rien vouloir cueillir de ces choses, de ces femmes, toutes si belles ${ }^{3}$ !

Dans Un homme pareil aux autres, René Maran évoque une différence de couleur de peau comme obstacle à la construction du couple. Dans le passage remarqué par Charles Scheel, il est question encore de la couleur de la peau. Mais de plus, d'une différence d'âge. Pourtant, le problème semble plus complexe. Le titre de la nouvelle est Une amie, et non Un amour. L'expression "amitié, » devant "amoureuse " semble, paradoxalement, rassurer l'auteur sur l'impossibilité de faire aboutir un projet de mariage. 
Fig. 1 : Feuillet manuscrit d'« Une amie », recto

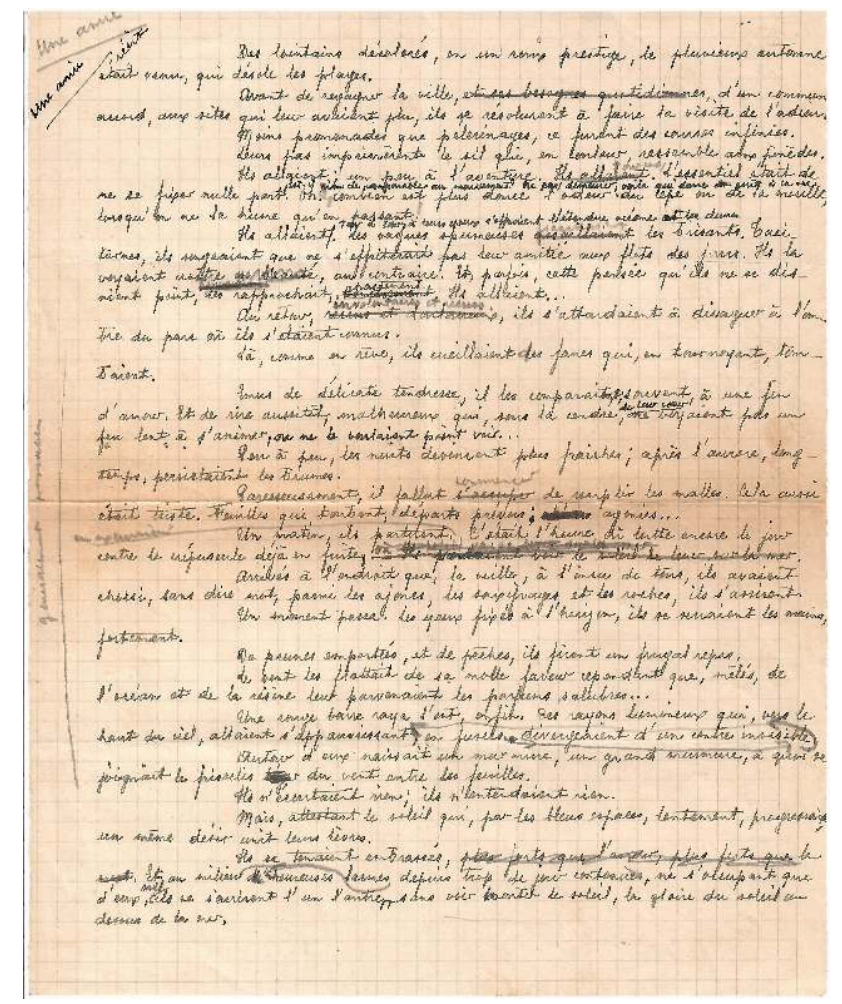

Fonds privé Bernard Michel

\section{ANNEXES}

\section{Une amie, récit}

Des lointains décolorés, en un roux prestige, le pluvieux automne était venu, qui désole les plages.

Avant de regagner la ville, et ses besognes quotidiennes, d'un commun accord, aux sites qui leur avaient plu, ils se résolurent à faire la visite de l'adieu.

Moins promenades que pèlerinages, ce furent des courses infinies.

Leurs pas imprimèrent le sil qui, en couleur, ressemble aux pinèdes.

Ils allaient ; un peu à l'aventure. Hs allaient. Pour eux, l'essentiel était de ne se fixer nulle part. Est-il rien de comparable au mouvement? Ne pas demeurer, voilà qui donne du goût à la vie. Oh ! Combien est plus douce l'odeur du cèpe ou de la morille, lorsqu'on ne la hume qu'en passant.

Ils allaient. Tour à tour, à leurs yeux s'offraient l'étendue océane et les dunes. Les vagues spumeuses assaillaient les brisants. Taciturnes, ils songeaient que ne s'effriterait pas leur amitié aux flots des jours. Ils la voyaient croître en beauté, au contraire. Et, 
parfois, cette pensée qu'ils ne se disaient point, les rapprochait, tendrement chastement. Ils allaient...

Au retour, recrus et douloureux involontaires et recrus, ils s'attardaient à divaguer à l'ombre du parc où ils s'étaient connus.

Là, comme en rêve, ils cueillaient des fanes qui, en tournoyant, tombaient.

Émus de délicate tendresse, il les comparait, souvent, à une fin d'amour. Et de rire aussitôt, malheureux qui, sous la cendre de leur cœur, ne voyaient pas un feu lent à s'animer, ou ne le voulaient point voir ...

Peu à peu, les nuits devinrent plus fraîches ; après l'aurore, longtemps, persistaient les brumes.

Paresseusement, il fallut s'occuper commencer à remplir les malles. Cela aussi était triste. Feuilles qui tombent, départs prévus ; agonies ...

Un matin, ils partirent en excursion. C'était l'heure où lutte encore le jour contre le crépuscule déjà en fuite. Hs voulaient voir le soleil se lever sur la mer.

Arrivés à l'endroit que, la veille, à l'insu de tous, ils avaient choisi, sans dire mot, parmi les ajoncs, les saxifrages et les roches, ils s'assirent.

Un moment passa. Les yeux fixés à l'horizon, ils se serraient les mains, fortement.

De prunes emportées, et de pêches, ils firent un frugal repas.

Le vent les flattait de sa molle faveur cependant que, mêlés, de l'océan et de la résine leur parvenaient les parfums salubres...

Une rouge barre raya l'est, enfin. Ses rayons lumineux qui, vers le haut du ciel, allaient s'appauvrissant, divergeaient d'un centre invisible, en fusées.

Autour d'eux naissait un murmure, un grand murmure, à quoi se joignait le friselis léger du vent entre les feuilles.

Ils n'écoutaient rien; ils n'entendaient rien.

Mais, attestant le soleil qui, par les bleus espaces, lentement, progressait, un même désir unit leurs lèvres.

Ils se tenaient embrassés, plus forts que l'amour, plus forts que la mort. Et, au milieu de larmes heureuses depuis trop de jours contenues, seuls, ne s'occupant que d'eux, ils s'ouvrirent l'un l'autre, sans voir monter le soleil, la gloire du soleil au-dessus de la mer.

\section{NOTES}

1. René Maran, lettre du 17 octobre 1913, de Fort Sibut.

2. Id., Un homme pareil aux autres, Paris, éditions Arc-en-ciel, 1947.

3. Id., lettre du 8 mai 1913, envoyée à Manoel Gahisto, de Grimari. 


\section{AUTEUR}

ROSELINE GARCIA BALLESTER

Doctorante, université de Besançon 